\title{
... denn sie wissen nicht, was sie tun.
}

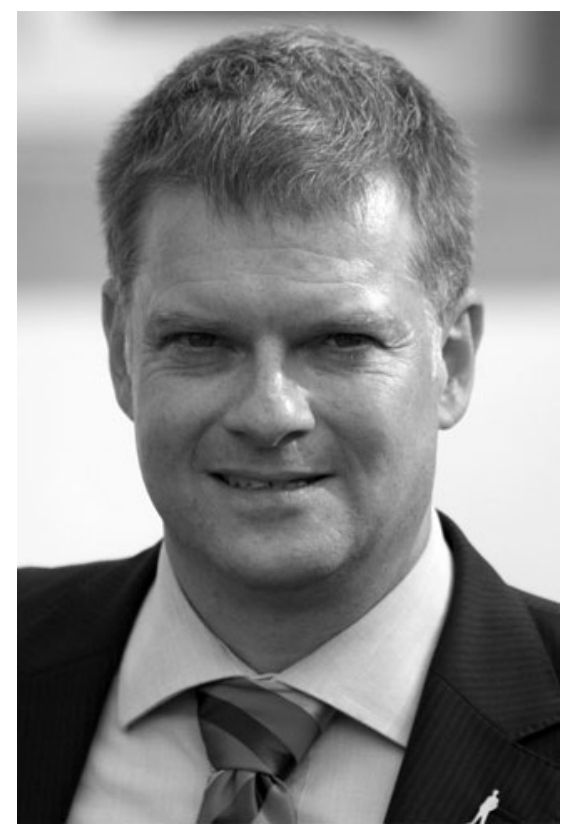

In den vergangenen 20 Jahren ist es endlich Schritt für Schritt gelungen, Sicherheit als eine wesentliche Eigenschaft eines IT-Systems zu verankern. Kaum ein Anbieter, der sich der Frage der Sicherheit eines neuen IT-Produkts nicht widmen würde - und sei es auf den letzten Metern vor der Markteinführung. Mindestens ein abschließendes Audit ist bei vielen Herstellern heute Pflichtprogramm, und nachträglich identifizierte, sicherheitsrelevante Fehler werden meist zügig durch Patches und Updates beseitigt. Das ist das Ergebnis eines mühsamen, oft von ebenso unangenehmen wie vermeidbaren Lernerfahrungen begleiteten langjährigen Prozesses.

Natürlich wünschen wir uns noch mehr, nämlich eine Berücksichtigung von Datenschutz und IT-Sicherheit bereits bei der Konzeption eines IT-Produkts ("Security and Privacy by Design"). Denn nur so lässt sich sicherstellen, dass Sicherheits- und Datenschutzanforderungen bereits in die Gestaltung der Lösung einfließen und nicht nachträglich hinzugebastelt werden (müssen). Einige Hersteller sind da bereits auf einem guten Weg und gewinnen immerhin mit "Security and Privacy by Default", d. h. datenschutz- und sicherheitsfreundlichen Voreinstellungen, Sympathien bei ihren Kunden.

Doch kaum sind IT-Produkte so weit, konterkariert das „Internet der Dinge" diese Entwicklung auf erschreckende Weise. Denn immer mehr Hersteller von Produkten, in denen Software eigentlich nur eine Nebenrolle spielt, statten ihre Produkte mit (oft kabellosen) Netzwerk-Anschlüssen aus - und erweitern sie dadurch um Möglichkeiten zur Fernsteuerung und Remote-Wartung.

Dabei passiert, was ohne vertiefte Kenntnisse über IT-Sicherheit und Datenschutz und ohne das Erlebnis des schmerzhaften Lernprozesses, den IT-Hersteller durchlaufen haben, passieren muss. Von den Resultaten lesen wir fast täglich in der Zeitung: Elektrische Skateboards lassen sich via Bluetooth unter fremde Kontrolle bringen. Kontaktlose "Smart-Keys" schalten das Fahrzeug einfach aus, wenn Mitfahrer sie während der Fahrt aus dem Fenster werfen. Ein Automobilhersteller liefert Autos mit Internet-Zugang, die sich während der Fahrt von unberechtigten Dritten steuern und manipulieren lassen - und bittet anschließend seine Kunden, einen Patch über das Internet herunterzuladen und via USB-Stick zu installieren. In den USA kommt ein 13.000 US\$ teures Präzisionsgewehr auf den Markt, bei dem Unberechtigte die Zieleinrichtung via WLAN umkonfigurieren können. Und immer mehr medizinische Geräte werden kabellos mit dem Krankenhaus-WLAN verbunden - in vielen Fällen ohne jede Schutzmaßnahme, die das Gerät, von dessen korrektem Funktionieren die Gesundheit eines Menschen abhängt, vor unberechtigten Zugriffen aus dem Netz bewahrt.

In Fragen der Sicherheit und des Datenschutzes scheint ungezügelte, von Kompetenz unvorbelastete Produktentwicklung im "Internet der Dinge“ wieder en vogue zu sein - ungeachtet der um ein Vielfaches größeren Gefahren, die dabei für Leben und Gesundheit drohen.

Wir können nur hoffen, dass die Lernkurve diesmal steiler und kürzer ausfällt.

\section{Dirk Fox}

